\title{
Reviews reviews Reviews
}

Reviews by Daniel Tsang,

University of California, Irvine.

Directory of Statistical Microcomputer Software. Wayne A. Woodward, Alan C. Elliot, Henry L. Gray. New York and Basel: Marcel Dekker, 1988.

The second edition of this statistical software directory, some two to three years after the first, is a massive 744-page book. Based on questionnaires to vendors, over 200 statistical software packages are analyzed. Entries contain hardware/software requirements, ordering/price information, available documentation and phone support, statistical features supported, graphic output product history, and occasionally, a listing published reviews. For SPSS-PC+, there is a citation to a review in the August 1986 issue of "American Statistician", but no review is listed for SAS. A useful feature is an appendix listing program capabilities for each program. Also useful is the name of a contact person at each vendor, although inevitably, that information will become dated readily. Rather surprising is the information given for the number of current users for the software package - from unknown to a dozen to thousands. A good source for the harder to find statistical package.

Cartographic and Remote-Sensing Digital Databases in the United Kingdom. Sarah Finch and David Rhind. Boston Spa, Wetherby, West Yorkshire: British Library, 1987.

This catalog of MRDF in cartography is part 6 in the British Library Information Gujde series. The subjects covered span not only oceanography or cartography, but also administrative and political divisions of Great Britain. Each entry describes the data file and lists the source. It may also list availability of hard copy output. Also sometimes given is compatability with particular statistical packages, such as SAS. In total 257 datasets are identified.

Of special interest is a short essay on "data archives and libraries," arguing that "if use of digital data and their transfer over telecommunications links become commonplace, then efficient storage of the digital records becomes essential."

It notes that back in 1984, the British House of Lords Select Committee on Science and Technology produced a report on remote sensing and digital mapping. Among its 46 recommendations was one calling on the British Library to preserve a retrospective archive of UK digital maps and remote sensing images. Subsequently, the British government decided the British Library should be an appropriate place for such an archive, and this book is a preliminary first step to survey the field. 
The essay concludes with a caution to be aware of "major difficulties" facing a library intent on archiving digital images: cost of acquisition, including the cost of obtaining adequate descriptions; the need for skilled staff, and the need to acquire hardware and software to store, retrieve and plot the data. A complete large-scale topographic map coverage of all of Britain would produce an estimated 16 gigabytes of data.

The book is a outcome of a project, begun in late 1984 and finished shortly thereafter in March, 1985, to compile an inventory of MRDF on cartography. Project director was David Rhind, a Professor of Geography at Birkbeck College, University of London; the research was done by Sara Finch. The MRDF identified in the book are not however, archived at the British Library.

In the US and Canada, the book is distributed by Longwood Publishing Group Inc., 27 S. Main St. Wolfeboro NH 03894-2069. 